\title{
Discussion on the Application of Discovery Learning in the Teaching Reformation of Chinese Universities
}

\author{
Xuejiao Wang \\ Political Science Academy, Xihua University, Chengdu, 610000, China
}

\begin{abstract}
Keywords: Discovery learning, Chinese University, Teaching reformation, Apply
Abstract: With the further development of Chinese teaching reformation, discovery learning attracts more attention. However, in current, this method has lower efficient which is caused by an immature theory and practice research. This paper will combine the current Chinese university education practice to explore its application in educate reformation and reflect its practice advantages and limitations exist.
\end{abstract}

\section{Problem statement}

Since the end of last century, with the unprecedented development of China's higher education, the number of college graduates has increased up to 7.27 million in 2014. Currently, China's higher education is mainly charged with two tasks, one is training personnel for the society, the other is to improve the overall literacy which requires to comply with the needs of social development, combining with the reality, ongoing education reform and innovation, using advanced teaching concepts and methods in practice.

Most of the current Chinese universities are accept the receptive learning method which has considerable advantages. First, it enables students to acquire more knowledge in a relatively short time, second, it can give full play of teacher's leading role and finally it helps students to cultivate the habit and ability to acquire knowledge from books. However, this teaching method is more suitable for secondary education while for college students, it is difficult to stimulate their internal motivation and enthusiasm to learn. Especially in the curriculum, basic and theoretical subjects occupy more percentage. The big distance between theory and practice results students prone to have dull weariness emotional state in the learning process even to have class just deal the naming and exam which is bad for deeper and comprehensive learning, and more difficult exists to tap their discipline potential and the motivation of creativity. Therefore, in the teaching of college students, it is necessary to stimulate their interest and guiding to establish a correct attitude and method toward learning. By this way, it not only be able to promote the smooth processing of teaching, but also training students' ability to explore and research, improving their ability of creativity.

Theory of discovery learning emphasizes the importance of leaner in the learning process which means stress their internal motivation. The advocator of discovery learning theory Bruner (Jerome S. Bruner, 1960s) thought although the learning and grasp the general theory and rules of a subject knowledge is important, the developing of a learning attitude to explore new situations is more significance, an attitude of make assumptions, speculate relations, to solve problems by personal ability or discovery new things. College learning has its unique features and their learning is more than learning subject knowledge, which is the formation and training of correct way of learning attitude and thinking to lay the foundation for maximize the development of creativity and potential. 


\section{Theory of discovery learning}

The contemporary American cognitive psychologist and educational psychologist Bruner proposed discovery learning theory after analyzed the disadvantages of tradition receptive learning in 1960s. He points out that the key to analyze student's study activities should be the internal cognitive process that they acquire knowledge and the method teachers using to organize class in order to realize the issue of promote students "knowledge discovery". Bruner believes that the best way to learn is by discovery learning. The so-called discovery learning means that students using textbook or conditions provided by teachers to thinking, found knowledge and master the principles and laws. It has many aspects of advantages, first, their inquiry spirit and problem-solving skills will be nurtured and improved, and this method helps to stimulate their internal motivation and activeness to learn, finally, discovery learning is also a creative learning process which can tap students' potential creativity and intelligence. From the perspective of teaching, teacher's right guidance enable students to learn activeness and generalize the principles or rules and feel happy and satisfied, thus find a strong motivation to learn and the knowledge has gained will be profound and not easily forgotten. Specifically, it refers the teacher do not provide ready-made answers but stimulate students' exploration psychology and guiding them to combining their own thinking characteristics and experiences to realize self-discovery and master the knowledge, and forming "migration" in the learning process, to draw inferences about other cases from one instance.

\section{The application of discovery learning in university teaching}

The colleges students are already have some subject knowledge structure and the ability of reasoning and problem exploration. So, it is an excellent teaching mode by create problem situation to guide students to explore and thinking to make an in-depth inquiry to achieve having certain experience and insights of what they have learned.

Generally, discovery teaching process has the following steps: first, create specific topic-related topic scenarios in which students find interesting problems; second, divided topic into several doubt inspire that must be answered to stimulate their spirit of inquiry; third, stimulate their creativity and encourage them to assume answers in innovation; fourth, guiding students to using cases, finishing materials and verifying their assumptions, it can be discussed if they have different opinions; fifth, "find" scientific conclusions and applied in practice. Finally, teachers summarize what students have discussed and solved. This teaching process not only enables students to master the method to solve problems, but also learns to promote those methods and thoughts, making the discipline being more structured and systematic, which good for memorize and knowledge transfer.

\section{Reflections caused by the application of discovery teaching}

Through higher teaching education practice, we found that discovery teaching method has its distinct advantages, mainly show in following aspects: first, it fully mobilize their activeness, and stimulate internal learning motivation, meanwhile, active the class atmosphere and gain a well effect; second, it also cultivate students' interest to explore and enhance the ability of observation, think and summary, developing their potential. In the discovery learning process, facing the problem they are interest in, students must access large amounts of data and after filter and summarize to form a logical proper and reasoned conclusions. The ability of think, analyze and summary will get exercised and improved, at the same time, it exploit their ability to solve problem creatively. Third, this teaching method also improved the ability of teamwork. When "found" 
"solve" each problem, student requires access to large amounts of data and achieved through a large demonstration, which rely on one student's strength is impossible to finish, and solving the problem often requires several students or a learning-group to cooperation. Therefore, in the process of problem solving, students' cooperation, communication and timely exchange are very important. As we all know, the rapid development of society can't realize without the cooperation and exchanges between people, thus, training and improve student's ability of interpersonal and assistance, promote their overall development is the ultimate goal of current education.

Of cause, the discovery teaching method is not perfect, there are some limitations that challenged current evaluation system in the teaching process.

First, the discovery teaching method requires students have a positive centripetal force which most of Chinese students lack of. This situation exists mainly for two reasons, one is students feel exhausted physically and mentally after the college entrance examination and the relatively relaxed learning environment in university suddenly let down their tight nerve, therefore most of them changed their own learning attitude in secondary school and the problem of homework plagiarism, boring classroom atmosphere and the problem of hard to establish a clear learning objectives often haunt them. In such a state of learning, it is hard to make students involved in learning activities actively. The other is the Chinese university general education course occupies a large percentage and contains a complex content, including a large number of ideological and political (Ideological Education), physical education, foreign language and other aspects of compulsory courses which has little relations with their professional courses, for this reason of disinterested with, the instructor is hard to mobilize their enthusiasm to explore, or guiding them to discover and solve problems wholeheartedly.

Second, the discovery teaching method takes more time than traditional teaching methods. Based on above discussion we know the discovery teaching method include several steps like assume problem condition, guiding students to think and make assumption or interpretation, access to information extraction points to solve the problem, testify the conclusion and others. In the process of hypothesis to conclusion, students need a lot of time to access and analyze data extraction which is difficult to realize in normal process of teaching.

Third, discovery teaching method has higher demand on teachers who must have a rich subject knowledge and the ability to flexibly handling classroom problems. Student's discovery learning dose not means arbitrary aimless "discovery". It refers under certain teaching objectives and requirements, teachers create problem situation to ensure students clear the question and do efforts to solve the problem with the guidance of teachers. In the self-exploration process of students, there is inevitably bring many problems and test to teachers. Therefore, before a class, teachers must have enough reserve of knowledge and the ability of summary and analysis to ensure is able to help students to grasp the crux of the problem, to enhance the understanding of problem and solving it creatively.

Finally, the discovery teaching method is not suitable for all classroom teaching, especially unsuitable for some mature theoretical teaching. So, it requires teacher combining with practice and using it flexibly.

The teaching practice shows that the flexible use of discovery teaching method in teaching process can play its function of stimulate the enthusiasm of students, active class atmosphere, cultivate their ability of creative learning. However, any kind of teaching method or teaching mode has its own advantages and disadvantages, and only by combining of various teaching methods and fully play their advantages to offset their weakness, can we get a better teaching effects and promote the smooth development of classroom teaching. 


\section{References}

[1] Meng Q. Compare and analysis on receptive learning and discovery learning. Journal of the Chinese Society of Education, 2003 (2): 27-29. (In Chinese)

[2] Chen Q, Liu R. Contemporary Educational Psychology. Higher Education Press, Beijing, 2005. (In Chinese)

[3] Zhao Y, Zhang X. retrospect and prospect on the study of Chinese and foreign learning method. Studies in Foreign Education, 2005 (4): 10-14. (In Chinese)

[4] Shi K. Design of microsatellite attitude control with multiplicative perturbation of controller//The 27th Chinese Control and Decision Conference. IEEE, 2015: 491-495.

[5] Lara J A, Lizcano D, Martínez M A, et al. A system for knowledge discovery in e-learning environments within the European Higher Education Area - Application to student data from Open University of Madrid, UDIMA[J]. Computers \& Education, 2014, 72(1):23-36. 